\title{
Phenotypical Characterization of Patients Who Underwent Perinatal Autopsy at the Hospital Universitario San Ignacio
}

\section{Caracterización fenotípica de pacientes sometidos a autopsia perinatal en el Hospital Universitario San Ignacio}

Received: 07 June 2018 | Accepted: 27 September 2018

\author{
Mercedes Olaya Contreras ${ }^{\mathrm{a}}$ \\ Pontificia Universidad Javeriana, Colombia \\ Rita Iris Ortega Rico ${ }^{b}$ \\ Pontificia Universidad Javeriana, Colombia \\ Olga Milena Moreno Niño ${ }^{c}$ \\ Pontificia Universidad Javeriana, Colombia \\ Fernando SuÁrez Obando ${ }^{\mathrm{d}}$ \\ Pontificia Universidad Javeriana, Colombia
}

a Surgeon, Pathologist. Internship in Pediatric Pathology. Doctorate in Biological Sciences. Associate Professor of the Department of Pathology, School of Medicine, Pontificia Universidad Javeriana, Bogotá, Colombia.

b MD. Medical Geneticist, School of Medicine, Pontificia Universidad Javeriana, Bogotá, Colombia.

c MD. Professor of the Institute of Human Genetics, School of Medicine, Pontificia Universidad Javeriana, Bogotá, Colombia.

d MD. Professor of the Institute of Human Genetics, School of Medicine, Pontificia Universidad Javeriana, Bogotá, Colombia.

How to cite: Olaya-CM, Ortega Rico RI, Moreno Niño OM, Suárez Obando F. Phenotypical Characterization of Patients Who Underwent Perinatal Autopsy at the Hospital Universitario San Ignacio. Univ. Med. 2019: 60(1). doi: https://doi.org/10.11144/Javeriana.ume d60-1.feno.

\begin{abstract}
Introduction: Chromosomal disorders cause a high mortality in the fetal and perinatal age group; however, cytogenetic or molecular studies are not routinely performed in our setting. Methods: Study where the morphology of patients subjected to perinatal autopsy in the HUSI during 2012 and 2013, with the diagnostic impression of chromosomal disorder, is characterized and the prenatal clinical characteristics are reviewed. Results: Forty-two cases were included. The majority of cases had placenta, corresponded to the second trimester of pregnancy (median of 15.5 weeks) and the mothers were $18-35$ years old. The morphological changes predominated in the head, neck and extremities. Conclusions: The knowledge of the morphological changes from perinatal autopsy is a tool that complements the analysis of mortality in this age group.

Keywords

autopsy; fetal death; congenital anomalies.
\end{abstract}

\section{RESUMEN}

Introducción: Los trastornos cromosómicos son causa de alta mortalidad en el grupo de edad fetal y perinatal; sin embargo, en el medio colombiano todavía no se realizan rutinariamente estudios citogenéticos o moleculares. Métodos: Estudio que caracteriza la morfología de pacientes sometidos a autopsia perinatal en el HUSI durante 2012 y 2013 con la impresión diagnóstica de trastorno cromosómico, y se revisan las características clínicas prenatales. Resultados: Se incluyeron 42 casos. La mayoría contaba con placenta, correspondían al segundo trimestre de la gestación (mediana de 15,5 semanas) y las madres estaban entre los 18 y los 35 años. Los cambios morfológicos predominaron en cabeza, cuello y extremidades. Conclusiones: El conocimiento de los cambios morfológicos a partir de la autopsia perinatal es una herramienta que complementa el análisis de la mortalidad en este grupo de edad.

Palabras clave

autopsia; muerte fetal; anomalías congénitas. 


\section{Introduction}

It is estimated that around $15 \%$ of all clinically recognizable pregnancies result in a spontaneous loss $(1,2)$, and that only between $30 \%$ and $40 \%$ result in a live birth (3); also that between 50\% and $70 \%$ of pregnancies result in a spontaneous abortion in the second trimester. The incidence of sporadic pregnancy losses is estimated between 1 and 300 (1). Some studies have found that $1 \%$ to $2 \%$ of women experience recurrent miscarriages (4).

The causes of spontaneous abortion and recurrent pregnancy loss include genetic, anatomical, infectious, immunological, endocrine and occupational etiologies $(1,5,6)$. Genetic etiology accounts for up to two thirds of spontaneous abortions, while autosomal aneuploidies account for up to $70 \%$ of fetal deaths, mainly in the first and second trimesters of pregnancy $(7,8,9,10,11,12,13,14)$.

Congenital anomalies are a major cause of miscarriage and perinatal mortality. In 2010, reports showed that the frequency of chromosomopathies in Bogotá was 21.7 per 10,000 live births (15), compared to 43 per 10,000 in the United States (16). In cases of fetal death, recurrent loss and spontaneous abortion, malformations occur in up to $12 \%$ of cases, which contrasts with $2 \%$ to $3 \%$ of malformations in live births $(17,18)$. The recurrence risk of serious congenital malformations increases from 2.5\% to $4.2 \%$ in neonates whose mothers have had three or more miscarriages (19). Similarly, there is an increased risk (OR: 1.43) for aneuploidy in children of patients who have had previous aneuploidy pregnancies (20).

Despite its importance, few studies have been conducted in Colombia on chromosomal disorders in miscarriages. In addition, in clinical practice, routine cytogenetic analyses of aborted fetuses or embryos are not performed, even in cases of repeated miscarriages or in fetuses with malformations, as can be seen in the routine of Colombia's pathology laboratories. Autopsies are not performed on all dead fetuses, and some of the autopsies that are performed are incomplete; only occasionally the autopsy is accompanied by a genetic study. In our country medical personnel have very little knowledge on the phenotypic characteristics present in chromosomopathies, even in the most frequent ones; due to this, the frequency of chromosomopathies in fetal and perinatal populations is unknown (21).

In this paper we describe the clinical and morphological characteristics of the population subjected to fetal and perinatal autopsy at the Hospital Universitario San Ignacio (HUSI) during 2012 and 2013, with a diagnosis of pathological anatomy suggestive of chromosomal disorder, in fetal patients attended in the hospital.

\section{Materials and methods}

Descriptive observational study of the universe of cases with the diagnostic impression of chromosomal disorder according to morphological findings. We evaluated all the clinical and anatomopathological characteristics described in the clinical history and in the autopsy report during the period described. The cases were identified in the HUSI Perinatal Pathology database with the diagnostic impression of chromosomal disorder. All the autopsies corresponded to natural deaths, all had parental authorization to carry them out and to include them in research studies. We excluded fetuses with a known, by anatomopathological or clinical data, specific cause of malformation different from chromosomopathies, morphological changes secondary to disruption, sequence, deformity or others.

We obtained the following variables from the clinical history: maternal age, parity, prenatal ultrasound diagnosis, prenatal cytogenetic results, gestational age, presence of intrauterine growth restriction, maternal diseases diagnosed before pregnancy, and obstetric complications. From the autopsy reports we analyzed several fetal phenotype variables and the description of major and minor malformations classified by systems. From the microscopic study of fetal organs we analyzed characteristics such as alterations in Hassall's corpuscles and dystrophic 
calcifications. From the anatomopathological study of the placenta, we analyzed alterations such as scalloped chorionic villi, deposits of calcium salts, trophoblast inclusions and villous cisterns. From the umbilical cord we identified coiling alterations, insertion, number of vessels and length. The association between morphological findings and clinical variables was evaluated by calculating the crude odds ratio (OR) analysis with 95\% confidence intervals (CI). The statistical analysis was carried out with the Stata 14.2 program.

\section{Results}

We identified a total of 42 cases of abortion and perinatal death with suspected chromosomal abnormalities between 2012 and 2013. In 35 cases (83\%) we analyzed both the fetus and the placenta. The median gestational age was 15.5 weeks, and the median maternal age was 32.5 years. In most cases there was a history of previous miscarriage; in 4 cases, mothers were classified as having recurrent pregnancy loss, that is, they had 2 or more previous miscarriages. According to gestational age, $81 \%$ occurred in the first trimester, and $9.5 \%$ in the second and third trimesters. $90.5 \%$ of cases had prenatal control. In 14 cases (37.8\%) abnormal ultrasound findings were described (discussed below). We observed that 3 of the 4 cases that did not have prenatal control presented major malformations (encephalocele, central defect of the closure of the abdominal wall, cleft lip, horseshoe kidney and single umbilical artery). We did not observe a higher frequency of maternal disease in the cases of anomalies. In only two cases exposure to teratogens (tobacco smoke and methotrexate) was reported; but the moment of suspension of consumption in relation to the beginning of the pregnancy or the magnitude of the consumption was not described. In both cases, consumption coincided with malformations; the case of methotrexate exposure presented gastroschisis and hypercoiling of the umbilical cord. In the case of exposure to tobacco smoke, trisomy 18 was confirmed by karyotype; the patient presented bilateral choroid plexus cysts, right microtia, single umbilical artery, right radial agenesis, reducible bilateral clubfoot, rocker bottom feet, mega cisterna magna, ventricular septal defect, and coarctation of the aorta.

The majority of anomalies (71.4\%) occurred in the fetuses of pregnant women aged 18-35 years. $12 \%$ had prenatal diagnosis by karyotype: two patients with monosomy $\mathrm{X}$, two with trisomy 18 and one with trisomy 21. In a case with a phenotype suggestive of Turner syndrome, the prenatal karyotype was normal. In $37.8 \%$, a prenatal ultrasound report was available. In all the cases with an ultrasound indicative of intrauterine growth restriction (9.5\%), heart disease was present.

When comparing the ultrasound and autopsy findings, clinical and anatomopathological findings were found in $42.8 \%$ of the cases that were not described in the prenatal ultrasound. We found that prenatal ultrasound and fetal autopsy findings coincided in $57.2 \%$ of the cases, especially in congenital heart diseases and fetal erythroblastosis (three cases) and clubfoot (two cases).

The anomalies most frequently not identified on ultrasound were single umbilical artery and clubfoot, in two cases each. The autopsy showed brachydactyly, rhizomelia, short neck, clinodactyly, microtia and claw hand, which had not been described in prenatal ultrasound. There was no specificity for any morphological finding in relation to clinical variables. Regarding phenotypic findings, we found malformations in all the systems, and grouped them according to their most frequent occurrence in the most common chromosomopathies.

We found placenta and umbilical cord alterations in $97.6 \%$ of the cases. Scalloped chorionic villi was the most frequent finding, with 23 cases. This, together with villous cisterns and trophoblast inclusions, constitutes the set of alterations that suggest underlying chromosomal alterations. In these cases, umbilical cord alterations are also frequent, such as coiling alterations (hypo- or hypercoiling), abnormal insertions, single umbilical artery and opposite coiling. Placental findings are similar for all cases, 
without distinctive statistical relationships with some morphological-fetal changes.

We identified 75 major and minor malformations. Abnormalities in the extremities were the most frequent, in $76.2 \%$ of the cases, followed by anomalies in the head and neck. The most frequent major anomaly was clubfoot, in 12 cases, and the most frequent minor anomaly was clinodactyly, in 16 cases. According to the occurrence of anomalies by systems, malformations occurred in the head and neck (37\%), extremities (26.6\%), cardiovascular system $(13.3 \%)$, genitourinary system $(8 \%)$, digestive system and abdomen (6.6\%), central nervous system (5.4\%) and thorax and lung $(2.7 \%)$. We classified the cases according to the most probable chromosomopathy, according to the phenotype, and we observed the changes in the umbilical cord and the placenta.

\section{Discussion}

In the literature reviewed, we did not find a significant gender difference in chromosomopathies (22). We also did not find a significant gender difference in our population (50\% female vs. $42.9 \%$ male).

Mean gestational age (15.5 weeks) was lower than that observed by Vimercati et al. (23) and Papp et al. (24), who reported 20.3 weeks (ultrasound and autopsy findings in cases of fetal malformations) and 22 weeks (fetal autopsy findings in cases of prenatal diagnosis of 13 , 18 and 21 trisomies), respectively. Another series, based on spontaneous abortions and genetic diagnosis, showed a lower average gestational age: 9.7 weeks (25). The differences in gestational age averages between some series reported in the literature depend on the selected ages; some include second-trimester fetuses, and others, such as the present study, include the first trimester of pregnancy. The distribution of abortions and perinatal deaths according to maternal age is similar to that described in the literature: there is a higher incidence in the group aged between 18 and 35 (73.8\%) (26,27) , followed by the group aged over 35 (23.8\%) and those below the age of 18 (2.4\%) (15).

It is noteworthy that there were no heart diseases or central nervous system abnormalities in the case of the minor pregnant woman or in those older than 35. Also that a case of gastroschisis was found in a pregnant woman of 39 years, contrary to what is described in the literature. The distribution of anomalies by systems that we found (head, neck and extremities) differed from that reported by Vimercati et al. (23): multiple anomalies, cardiovascular anomalies (19\%) and central nervous system anomalies (16\%). We do not rule out underdiagnosis of the latter in our population, given the high number of individuals with maceration, which makes it very difficult to evaluate the central nervous system in the autopsy, due to the changes caused by liquefaction. For this purpose, nuclear magnetic resonance prior to autopsy is recommended (28).

The differences found between ultrasound and autopsy findings were larger than those found in the literature (12\%) (23). On the other hand, the coincidence between these findings was superior to other observations (49\% and 51.1\%) $(23,29)$. The literature on the subject says that prenatal ultrasound findings have a false positive and false negative diagnosis rate (13), so the contribution of the anatomopathological study of the fetus is a valuable tool to assess the accuracy of prenatal ultrasound and to complete the findings, in order to improve diagnostic accuracy $(23,24)$. In our environment, where genetic study is not routine, fetal autopsy provides morphological and etiological information (29).

In most cases, the fetal autopsy includes a study of the placenta. Abnormalities were often found in the placenta and the umbilical cord; these are also common to all chromosomopathies, so they do not allow to differentiate between them. However, they are useful to support the diagnostic suspicion of chromosomal disorder, mainly when the fetus is very small and its changes are very subtle. A similar role is fulfilled by some fetal anomalies common to several chromosomopathies, such as cervical macrocystic lymphatic malformation 
(cystic hygroma), axillary pterygium and brachydactyly.

\section{Conclusions}

We analyzed the morphological characteristics of fetal autopsies, and they were found more frequently in the head, neck and extremities. The placenta presents concomitant changes with the fetus. Undoubtedly, phenotypic findings are not enough to differentiate between chromosomopathies, so it is necessary to confirm the diagnosis by cytogenetic or molecular techniques. However, we confirmed that fetal autopsy is a useful complementary tool to evaluate the accuracy of prenatal ultrasound, and to guide cases of suspected chromosomal alterations.

\section{References}

1. Ford HB, Schust DJ. Recurrent pregnancy loss: etiology, diagnosis, and therapy. Rev Obstet Gynecol. 2009;2(2):76-83.

2. Sakamoto A, Kamada Y, Kubo K, Hasegawa T, Kotani S, Nakatsuka M, et al. Slow fetal heart rate before miscarriage in the early first trimester predicts fetal aneuploidy in women with recurrent pregnancy loss. Acta Med Okayama. 2018;72(1):61-6.

3. Macklon NS, Geraedts JPM, Fauser BCJM. Conception to ongoing pregnancy: the "black box" of early pregnancy loss. Hum Reprod Update. 2002;8(4):333-43.

4. Stephenson MD. Frequency of factors associated with habitual abortion in 197 couples. Fertil Steril. 1996;66(1):24-9.

5. Kutteh WH. Novel strategies for the management of recurrent pregnancy loss. Semin Reprod Med. 2015;33(3):161-8.
6. Forero M, Lucena E, Esteban C. Frecuencia de mosaicismos de baja proporción del cromosoma $\mathrm{x}$ en parejas con antecedente de aborto recurrente. Rev Cienc Salud. 2006;4(supl 1):23-45.

7. Haoud K, Mellali S, Gouas L, Tchirkov A, Vago P, Moulessehoul S. Prevalence of aneuploidies in products of spontaneous abortion: interest of FISH and MLPA. Morphologie. 2014;98(320):40-6.

8. Horn L-C, Langner A, Stiehl P, Wittekind C, Faber R. Identification of the causes of intrauterine death during 310 consecutive autopsies. Eur J Obstet Gynecol Reprod Biol. 2004;113(2):134-8.

9. Stocker JT. The pediatric autopsy. En: Stocker JT, Dehner LP HA, editores. Pediatric pathology. 3rd ed. Philadelphia: Lippincott Williams and Wilkins; 2011. p. 1-18.

10. McFadden D. First and second trimester pregnancy loss. In: Stocker JT, Dehner LP HA, editores. Pediatric pathology. 3rd ed. Philadelphia: Lippincott Williams and Wilkins; 2011. p. 56-71.

11. van den Berg MMJ, van Maarle MC, van Wely M, Goddijn M. Genetics of early miscarriage. Biochim Biophys Acta. 2012;1822(12):1951-9.

12. Kapur RP SJ. Chromosomal abnormalities. En: Stocker JT, Dehner LP HA, editores. Pediatric pathology. 3rd ed. Philadelphia: Lippincott Williams and Wilkins; 2011. p. 72-93.

13. Khong TY. Spontaneous abortion and the pathology of early pregnancy. En: Keeling JW KT, editor. Fetal and neonatal pathology. 4th ed. London: Springer; 2007. p. 102-22.

14. Ruiz-Ruiz J, Corredor-Sánchez E, García-Perlaza C, Madero-Cervera J, López C, León M et al. Embrioscopía 
en aborto retenido. Rev Colomb Obstet Ginecol. 2006;57:207-10.

15. Zarante I, Franco L, López C FN. Frecuencia de malformaciones congénitas: evaluación y pronóstico de 52.744 nacimientos en tres ciudades colombianas. Biomédica. 2010;30:65-71.

16. Park S-J, Jung EH, Ryu R-S, Kang HW, Chung HD, Kang H-Y. The clinical application of array $\mathrm{CGH}$ for the detection of chromosomal defects in 20,126 unselected newborns. Mol Cytogenet. 2013;6(1):21.

17. Heinonen OP. Spontaneous abortions, stillbirths and birth defects in epidemiological search for risk indicators. Dev Toxicol Environ Sci. 1986;12:63-76.

18. Morales J, Luna L, Mutchinick M. Epidemiología de las malformaciones congénitas. En: Del Castillo Ruiz V, Dulijh R, Zafra de la Roa G, editores. Genética clínica. México D. F.: Manual Moderno; 2001. p. 345-50.

19. Khoury MJ, Erickson JD. Recurrent pregnancy loss as an indicator for increased risk of birth defects: a population-based case-control study. Paediatr Perinat Epidemiol. 1993;7 (4):404-16.

20. Kort JD, McCoy RC, Demko Z, Lathi RB. Are blastocyst aneuploidy rates different between fertile and infertile populations? J Assist Reprod Genet. 2018;35(3):403-8.

21. García R, García N, Olaya M, Suárez-Obando F. El mortinato y el mortinato malformado como urgencias médicas: propuesta de manejo interdisciplinario. Pediatría (Santiago). 2010;43(3):166-76.

22. Zarante AM, García G, Zarante I. Evaluación de factores de riesgo asociados con malformaciones congénitas en el programa de vigilancia epidemiológica de malformaciones congénitas (ECLAMC) en Bogotá entre 2001 y 2010. Univ Méd. 2012;53(1):11-25.

23. Vimercati A, Grasso S, Abruzzese M, Chincoli A, de Gennaro A, Miccolis A, et al. Correlation between ultrasound diagnosis and autopsy findings of fetal malformations. J Prenat Med. 2012;6(2):13-7.

24. Papp C, Szigeti Z, Joó JG, TóthPál E, Hajdú J, Papp Z. The role of perinatal autopsy in the management of pregnancies with major fetal trisomies. Pathol Res Pract. 2007;203(7):525-31.

25. Mora-Alferez P, Paredes D, Rodríguez O, Quispe E, Chavesta F, Klein de Zighelboim E, et al. Anomalías cromosómicas en abortos espontáneos. Rev Peru Ginecol y Obstet. 2016;62(2):141-51.

26. Muñetón C, Ramírez J, Vásquez G, Agudelo B. Estudios citogenético y morfológico en producto de aborto espontáneo procedentes de diferentes servicios de ginecoobstetricia de la ciudad de Medellín. Iatreia [Internet]. 1998;11(4):145-61. Disponible en: https://aprendeenlinea. udea.edu.co/revistas/index.php/iatreia/ article/view/3666.

27. Piercecchi-Marti MD, Liprandi A, Sigaudy S, Fredouille C, Adalian P, Figarella-Branger D, et al. Value of fetal autopsy after medical termination of pregnancy. Forensic Sci Int. 2004;144(1):7-10.

28. Woodward PJ, Sohaey R, Harris DP, Jackson GM, Klatt EC, Alexander $\mathrm{AL}$, et al. Postmortem fetal MR imaging: comparison with findings at autopsy. AJR Am J Roentgenol. 1997;168(1):41-6.

29. Starikov $R$, Inman $K$, Chen $K$, Lopes V, Coviello E, Pinar H, et al. Comparison of placental findings in type 1 and type 2 diabetic pregnancies. Placenta. 2014;35(12):1001-6. 